\title{
Risk Factors for Epithelial Ovarian Tumours of Borderline Malignancy
}

\author{
FABIO PARAZZINI,* CARLO RESTELLI," † CARLO LA VECCHIA,*,** EVA NEGRI,* STEFANIA \\ CHIARI, $\ddagger$ RENATO MAGGI† AND COSTANTINO MANGIONI
}

Parazzini F (Istituto di Ricerche Farmacologiche 'Mario Negri', via Eritrea 62, 20157 Milano, Italy), Restelli C. La Vecchia C, Negri E, Chiari S, Maggi R and Mangioni C. Risk factors for epithelial ovarian tumours of borderline malignancy. International Journal of Epidemiology 1991; 20: 871-877.

A case-control study was conducted on 91 cases with histologically-confirmed borderline ovarian tumours and 237 control subjects in hospital for acute non-gynaecological, hormonal or neoplastic disease. Women reporting three or more births, compared to nulliparae, had a relative risk (RR) estimate of 0.6 , but this finding was not statistically significant (95\% confidence interval (CI): 0.2-1.4). The risk of borderline tumours increased, although not significantly, with later age at first birth: compared to women reporting first birth at age 24 or before, the RRs were 1.3 and 1.7 in those reporting respectively their first birth at age $25-29$ and 30 years or more. No significant relationship emerged between borderline ovarian cancer and age at menarche, menopausal status and lifelong menstrual pattern. Cases tended to report a later age at menopause than controls, but the trend in risk was not statistically significant. Nine cases (9.9\%) and 68 controls $(24.9 \%)$ reported oral contraceptive use: compared with never users the multivariate RR for ever users was 0.3 , and the risk dropped with duration of use to 0.2 in users for two years or more $\left(X^{2}\right.$, trend $\left.=12.70, p<0.001\right)$. This study provides epidemiological evidence of a pathogenetic continuum between borderline and invasive ovarian tumours.

Borderline ovarian tumours amount to about $10-15 \%$ of malignant ovarian tumours in the epithelial category. They show many histological characteristics of malignancy, including increased mitotic activity, nuclear abnormalities, multilayering of cells, but do not invade the ovarian stroma, the frequency of their extraovarian spread is low and their clinical course is characterized by low malignancy and high survival rates. ${ }^{1,2}$

Descriptive epidemiological studies and clinical series have shown that borderline ovarian tumours are relatively more common in younger women than invasive carcinomas, and their incidence, as for malignant epithelial neoplasia, is lower in non-white than in white women. ${ }^{3}$ Further, the few available analytical epidemiological data suggest that borderline neoplasia may share risk factors (e.g. parity or oral contraceptive use) with invasive cancer, ${ }^{4,5}$ but no association was found between borderline ovarian tumours and a family history of ovarian cancer (a recognized risk factor for invasive tumours) $)^{5-8}$ in two case-control studies conducted in the US. ${ }^{8,9}$

*Istituto di Ricerche Farmacologiche 'Mario Negri', via Eritrea 62, 20157 Milano, Italy.

**Institute of Social and Preventive Medicine, University of Lausanne, Switzerland.

†Seconda Clinica Ostetrico-Ginecologica, Università di Milano, Italy. tQuarta Clinica Ostetrico-Ginecologica, Università di Milano, Italy.
To obtain further information on the epidemiology of borderline ovarian tumours, we considered data from a case-control study conducted in the greater Milan area, Northern Italy.

\section{SUBJECTS AND METHODS}

Since 1986 we have been conducting a case-control study of borderline ovarian tumours. Trained interviewers identified and questioned women with borderline ovarian tumour and control subjects. All interviews were conducted in hospital.

Cases were women aged less than 65 years with histologically-confirmed diagnosis of borderline ovarian tumour (according to the World Health Organization criteria ${ }^{10}$ ) who were admitted to the Second and Fourth Obstetrics and Gynaecology Clinic of the University of Milan. A total of 91 women aged 23 to 64 years were interviewed. Potential control subjects were women below the age of 65 admitted for acute non-gynaecological, non-hormonal and non-neoplastic conditions to the Ospedale Maggiore (including the four major teaching and general hospitals in Milan) and several specialized university clinics, serving a catchment area comparable to that of the hospitals where cases had been identified. They were recruited within the framework of a case-control surveillance of female genital neoplasms." Out of a total of 2625 subjects interviewed, 273 controls were 
selected (age range 24-64 years), matched in a 1:3 ratio within strata of five-year age groups. Of these, $30 \%$ were admitted for traumatic conditions (mostly fractures and sprains), $28 \%$ had non-traumatic orthopaedic disorders (mostly low back pain and disk disorders), $17 \%$ acute abdominal diseases generally requiring surgery, and $25 \%$ other miscellaneous illnesses, such as disorders of the ear, nose, throat or teeth. Less than $2 \%$ of cases and controls refused to be interviewed. Information was obtained, using a structured questionnaire, on personal characteristics and habits, gynaecological and obstetric data, related medical history, lifetime oral contraceptive or other female hormone use. Lifelong menstrual pattern was defined by asking patients whether their lifelong menstrual pattern was 'regular' or 'irregular' (frequent menstrual-like episodes of bleeding less than 21 or more than 35 days apart). Women were defined as postmenopausal if their last menstrual period occurred more than one year before the interview. The present report is based on data collected up to June 1990.

\section{Data Analysis}

Odds ratios, as estimators of relative risks (RR), of borderline ovarian cancer, together with their $95 \%$ approximate confidence intervals $(\mathrm{Cl})$, were first com- puted from data stratified for age by the MantelHaenszel procedure. ${ }^{12}$ When a factor could be classified in more than two ordered levels, the significance of the linear trend was assessed by the Mantel test. $^{13}$

To account simultaneously for the effects of several potential confounding factors, we used unconditional multiple logistic regression, with maximum likelihood fitting. ${ }^{14}$ Included in the regression equations were terms for age, education, parity, oral contraceptive use, age at menopause and, in turn, the other factors considered.

\section{RESULTS}

The distribution of cases and controls according to age and other major sociodemographic factors (education and marital status) is shown in Table 1. Cases and controls were similar with reference to education and marital status: the RR estimates were $1.3(95 \% \mathrm{CI}$ : 0.6-2.7) for 12 years of education or more as compared to less than seven, and $1.1(95 \% \mathrm{CI}: 0.6-2.0)$ for married versus never married women (Table 1).

The distribution of cases and controls according to menstrual history is presented in Table 2 . No relationship emerged between borderline ovarian cancer risk and age at menarche, menopausal status and lifelong

TABLE 1 Distribution of 91 cases of borderline ovarian cancer and 273 controls (and corresponding relative risks) according to age, education and marital status. Milan, Italy, 1983-1990

\begin{tabular}{|c|c|c|c|c|c|c|}
\hline & \multicolumn{2}{|c|}{ Cases } & \multicolumn{2}{|c|}{ Controls } & \multicolumn{2}{|c|}{ Relative risk $(95 \% \mathrm{CI})$} \\
\hline & & & & & Mantel-Haenszel & $\begin{array}{l}\text { Multiple logistic } \\
\text { regression** }\end{array}$ \\
\hline \multicolumn{7}{|l|}{ Age (years) } \\
\hline$<30$ & 31 & (34.1) & 86 & (31.5) & - & - \\
\hline $30-39$ & 16 & (17.6) & 55 & (20.1) & - & - \\
\hline $40-49$ & 12 & (13.2) & 36 & $(13.2)$ & - & - \\
\hline $50-59$ & 19 & (20.9) & 57 & (20.9) & - & - \\
\hline $60-64$ & 13 & $(14.3)$ & 39 & (14.3) & - & - \\
\hline \multicolumn{7}{|c|}{ Education (years) } \\
\hline$\leqslant 6$ & 32 & (35.2) & 102 & (37.4) & It & $1 \dagger$ \\
\hline $7-11$ & 28 & (30.8) & 92 & (33.7) & $\begin{array}{c}1.0 \\
(0.5-2.0)\end{array}$ & $\begin{array}{c}1.0 \\
(0.5-2.0)\end{array}$ \\
\hline$\geqslant 12$ & 31 & (34.1) & 79 & $(28.9)$ & $\begin{array}{c}1.3 \\
(0.6-2.7)\end{array}$ & $\begin{array}{c}1.2 \\
(0.6-2.4)\end{array}$ \\
\hline$\chi^{2}$, trend & & & & & $0.70(p=0.40)$ & $0.22(p=0.64)$ \\
\hline \multicolumn{7}{|l|}{ Marital status } \\
\hline Never married & 27 & (29.7) & 81 & $(29.7)$ & $1+$ & $1 \dagger$ \\
\hline Ever married & 64 & $(70.3)$ & 192 & $(70.3)$ & $\begin{array}{c}1.1 \\
(0.6-2.0)\end{array}$ & $\begin{array}{c}1.2 \\
(0.6-2.4)\end{array}$ \\
\hline
\end{tabular}

* Adjusted for age.

**Including terms for age, education, parity, oral contraceptive use, age at menopause and the above listed variables. †Reference category. 
TABLE 2 Distribution of 91 cases of borderline ovarian cancer and 273 controls (and corresponding relative risks) according to selected menstrual characteristics. Milan, Italy, 1983-1990

\begin{tabular}{|c|c|c|c|c|}
\hline & \multirow[t]{2}{*}{ Cases } & \multirow[t]{2}{*}{ Controls } & \multicolumn{2}{|c|}{ Relative risk $(95 \% \mathrm{CI})$} \\
\hline & & & Mantel-Haenszel* & $\begin{array}{l}\text { Multiple logistic } \\
\text { regression** }\end{array}$ \\
\hline \multicolumn{5}{|c|}{ Age at menarche (years) } \\
\hline$\leqslant 12$ & 41 & 121 & $\cdot 1 \dagger$ & $1 \dagger$ \\
\hline $13-14$ & 39 & 120 & $\begin{array}{c}0.9 \\
(0.6-1.6)\end{array}$ & $\begin{array}{c}1.0 \\
(0.6-1.8)\end{array}$ \\
\hline$\geqslant 15$ & 11 & 32 & $\begin{array}{c}1.1 \\
(0.5-2.4)\end{array}$ & $\begin{array}{c}1.1 \\
(0.5-2.5)\end{array}$ \\
\hline$\chi_{1}^{2}$ trend & & & $0.00(p=0.97)$ & $0.06(p=0.81)$ \\
\hline \multicolumn{5}{|l|}{ Menopausal status } \\
\hline Pre/in menopause & 63 & 181 & $1+$ & $1 \uparrow$ \\
\hline Postmenopause & 28 & 92 & $\begin{array}{c}0.8 \\
(0.4-1.6)\end{array}$ & $\begin{array}{c}0.5 \\
(0.2-1.7)\end{array}$ \\
\hline \multicolumn{5}{|c|}{ Age at menopause (years) } \\
\hline$\leqslant 50$ & 7 & 39 & $1 \dagger$ & $1+$ \\
\hline $50-53$ & 17 & 42 & $\begin{array}{c}2.1 \\
(0.8-5.9)\end{array}$ & $\begin{array}{c}2.7 \\
(0.9-7.6)\end{array}$ \\
\hline$\geqslant 54$ & 4 & 11 & $\begin{array}{c}2.0 \\
(0.5-9.0)\end{array}$ & $\begin{array}{c}2.3 \\
(0.5-10.2)\end{array}$ \\
\hline$\chi^{2}{ }_{1}$ trend & & & $1.31(p=0.25)$ & $2.35(p=0.13)$ \\
\hline Lifelong menstrual & & & & \\
\hline Regular & 73 & $229 \ddagger$ & $1 \dagger$ & $1 \dagger$ \\
\hline Irregular & 18 & 43 & $\begin{array}{c}1.3 \\
(0.7-2.4)\end{array}$ & $\begin{array}{c}1.3 \\
(0.6-2.4)\end{array}$ \\
\hline
\end{tabular}

menstrual pattern. Postmenopausal cases tended to report a later age at menopause than controls, but the trend in risk was not statistically significant $\left(\mathrm{X}^{2}{ }_{1}\right.$ trend $1.31, \mathrm{p}=0.25$ ).

Women reporting three or more births were at lower risk of borderline ovarian cancer than nulliparae, but this finding (and the overall trend in risk for parity) was not significant (Table 3). The risk increased with later age at first birth and, compared to parous women reporting first birth at age 24 or before, was 1.8 and 2.5 in those reporting first birth at age 25-29 and 30 or more respectively. This trend in risk was significant $\left(\mathrm{X}_{1}{ }_{1}\right.$ trend $\left.=5.11, \mathrm{p}=0.02\right)$. There was no association between spontaneous abortions and borderline ovarian cancer, but the risk estimate was lower in women who reported one or more induced abortions than in those who had none (RR $0.2,95 \% \mathrm{CI}$ : $0.1-0.6$ ).

The distribution of cases and controls according to oral contraceptive use is shown in Table 4. Nine cases $(9.9 \%)$ and 68 controls $(24.9 \%)$ reported oral con- traceptive use: compared with never users, the ageadjusted RR for ever users was 0.3 (95\% CI: $0.2-0.7$ ) and the risk decreased to 0.2 in users for two years or more $\left(\mathrm{X}^{2}\right.$, trend $\left.=10.10, \mathrm{p}<0.001\right)$.

Multivariate RR estimates were generally consistent with age-adjusted ones, with the exception of estimates for age at first birth which tended to be closer to unity; the corresponding multivariate trend in risk was consequently not statistically significant.

\section{DISCUSSION}

The findings of this study indicate that the risk of borderline ovarian malignancies was lower in oral contraceptive users and decreased with duration of use. A higher risk emerged in women reporting late age at first birth, in those with no history of induced abortion, late age at menopause and in nulliparae (but the latter two findings were not significant).

A major limitation of this study is the small sample size and hence its limited statistical power. This is due to the rarity of the disease and should be 
TABLE 3 Distribution of 91 cases of borderline ovarian cancer and 273 controls (and corresponding relative risks) according to reproductive variables. Milan, Italy, 1983-1990

\begin{tabular}{|c|c|c|c|c|}
\hline & \multirow[t]{2}{*}{ Cases } & \multirow[t]{2}{*}{ Controls } & \multicolumn{2}{|c|}{ Relative risk $(95 \% \mathrm{CI})$} \\
\hline & & & Mantel-Haenszel* & $\begin{array}{l}\text { Multiple logistic } \\
\text { regression** }\end{array}$ \\
\hline \multicolumn{5}{|l|}{ Parity } \\
\hline 0 & 36 & 101 & $1 \dagger$ & 14 \\
\hline $1-2$ & 44 & 118 & $\begin{array}{c}1.0 \\
(0.5-1.9)\end{array}$ & $\begin{array}{c}1.1 \\
(0.6-2.1)\end{array}$ \\
\hline$\geqslant 3$ & 11 & 54 & $\begin{array}{c}0.7 \\
(0.2-1.8)\end{array}$ & $\begin{array}{c}0.6 \\
(0.2-1.4)\end{array}$ \\
\hline$\chi_{1}^{2}$ trend & & & $1.46(p=0.23)$ & $1.54(\mathrm{p}=0.21)$ \\
\hline \multicolumn{5}{|c|}{ Spontaneous abortions } \\
\hline 0 & 80 & 234 & $1+$ & it \\
\hline$\geqslant 1$ & 11 & 39 & $\begin{array}{c}0.8 \\
(0.4-1.8)\end{array}$ & $\begin{array}{c}0.9 \\
(0.4-2.0)\end{array}$ \\
\hline \multicolumn{5}{|c|}{ Induced abortion } \\
\hline 0 & 88 & 233 & $1 \dagger$ & $1 \dagger$ \\
\hline$\geqslant 1$ & 3 & 40 & $\begin{array}{c}0.2 \\
(0.1-0.6)\end{array}$ & $\begin{array}{c}0.2 \\
(0.1-0.8)\end{array}$ \\
\hline \multicolumn{5}{|c|}{ Age at first birth (years) } \\
\hline$\leqslant 24$ & 25 & 107 & $1 \dagger$ & $1 \uparrow$ \\
\hline $25-29$ & 19 & 46 & $\begin{array}{c}1.8 \\
(0.9-3.6)\end{array}$ & $\begin{array}{c}1.3 \\
(0.6-2.8)\end{array}$ \\
\hline$\geqslant 30$ & 11 & 19 & $\begin{array}{c}2.5 \\
(1.0-6.1)\end{array}$ & $\begin{array}{c}1.7 \\
(0.6-4.6)\end{array}$ \\
\hline$x_{1}^{2}$ trend & & & $5.11(\mathrm{p}=0.02)$ & $1.23(\mathrm{p}=0.27)$ \\
\hline
\end{tabular}

*Adjusted for age.

**Including terms for age, education, parity (when appropriate), oral contraceptive use, age at menopause and the above listed variables.

†Reference category.

TABLE 4 Distribution of 91 cases of borderline ovarian cancer and 273 controls (and corresponding relative risks) according 10 oral contraceptive use. Milan, Italy, 1983-1990

\begin{tabular}{ll} 
Cases Controls $\quad$ Relative risk $(95 \% \mathrm{CI})$ \\
\hline
\end{tabular}

Mantel-Haenszel* Multiple logistic
regression**

Oral contraceptive use

Never used

Ever used

$\begin{array}{rr}82 & 205 \\ 9 & 68\end{array}$

205
68

17

17

$(0.2-0.7)$

$(0.2-0.6)$

Duration of use (months)

$<24$

$5 \quad 30$

0.3

$(0.1-0.9)$

0.2

0.3

$\geqslant 24$

4

38

(0.1-0.7)

$\chi^{2}{ }_{1}$ trend

$10.10(p<0.001)$

0.2

(0.1-0.6) $12.70(p<0.001)$

* Adjusted for age.

* Including terms for age, education, parity, age at menopause and oral contraceptive use.

tReference category. 
TABLE 5 Relative risk estimates of borderline and invasive ovarian cancer emerging from a case-control survey conducted in the greater Milan area (present study and 20, 30, 32). 1983-1990

\begin{tabular}{|c|c|c|}
\hline & \multicolumn{2}{|c|}{ Relative risk } \\
\hline & $\begin{array}{c}\text { Borderline } \\
\text { tumours }\end{array}$ & $\begin{array}{c}\text { Malignant } \\
\text { tumours }\end{array}$ \\
\hline \multicolumn{3}{|l|}{ Parity } \\
\hline 0 & $1 \dagger$ & $1 \dagger$ \\
\hline 1 & 1.1 & 0.7 \\
\hline$\geqslant 2$ & 0.6 & 0.7 \\
\hline \multicolumn{3}{|c|}{ Age at first birth (years) } \\
\hline$<22$ & it & $1 \dagger$ \\
\hline $22-24$ & & 2.9 \\
\hline $25-27$ & $1.3^{*}$ & 3.0 \\
\hline$\geqslant 28$ & $1.7 * *$ & 3.3 \\
\hline \multicolumn{3}{|c|}{ Age at menarche (years) } \\
\hline$\geqslant 13$ & $1 \uparrow$ & $1 \dagger$ \\
\hline$<13$ & 1.0 & 1.1 \\
\hline \multicolumn{3}{|c|}{ Age at menopause (years) } \\
\hline$<45$ & $1 \dagger$ & $1 \dagger$ \\
\hline $45-49$ & & 1.3 \\
\hline $50-53$ & 2.7 & 1.4 \\
\hline$\geqslant 54$ & 2.3 & 1.6 \\
\hline \multicolumn{3}{|c|}{ Oral contraceptive use (years) } \\
\hline Never & $1 \dagger$ & $1 \dagger$ \\
\hline$<2$ & 0.3 & 0.9 \\
\hline$\geqslant 2$ & 0.2 & 0.5 \\
\hline
\end{tabular}

considered in the interpretation of results. In relation to potential biases, selection should not markedly influence the findings since cases and controls were identified in institutions covering comparable catchment areas and participation was almost complete. Our control group consisted of women in hospital for a large number of acute conditions, and it is conceivable that specific conditions may be selectively associated with some of the factors considered. For example trauma is associated with osteoporosis, which, in turn, is possibly related with obstetric and reproductive history. ${ }^{15}$ However the RR estimates were largely consistent when analysis was performed considering separately main categories of controls (trauma, other orthopaedics, surgical and other). Furthermore, hospital controls are likely to provide information more comparable to that of cases than population controls. Our interviewers were not blind to the case-control status, but they were not aware of the specific endpoints of this analysis. In general, it is unlikely that information bias is a major problem in the definition of reproduc- tive and menstrual characteristics or of general lifestyle or socioeconomic indicators, particularly in younger women. ${ }^{16}$ With regard to confounding, allowing for potential covariates did not materially modify the estimated RRs.

Few analytical epidemiological studies have been published on risk factors for borderline ovarian cancer. This study provides further data on the issue and allows comparison with studies on the epidemiology of malignant ovarian tumours. Two case-control studies conducted in the US on borderline ovarian malignancies found a negative association with increasing parity ${ }^{4,5}$ and an increased risk of the disease associated with number of miscarriages emerged in one study. ${ }^{4}$ In the present study the protection given by parity was restricted to multiparae (and not statistically significant, possibly because of the small sample size). Late age at first birth was associated with an increased risk in this study, but not in a previous one. ${ }^{4}$

The lower risk of borderline ovarian cancer observed in this study in women reporting induced abortions can be tentatively interpreted in terms of higher fertility in women requiring induced abortions. ${ }^{17,18} \mathrm{~A}$ greater risk of borderline ovarian cancer in ever-married nulliparous women reporting a history of infertility was also observed in an American casecontrol study. ${ }^{4}$

The role of parity and early age at first birth ${ }^{19-21}$ in ovarian carcinogenesis is incompletely understood, the relevant issue being whether nulliparity per se or difficulty in conception facilitates the development of ovarian cancer. Most studies on malignant disease report a lower risk in parous than in nulliparous women, but the protection provided by more than one pregnancy is generally weak. ${ }^{17}$ Furthermore, since multiparous women usually start reproduction early in their life, the independent effects of age at first birth and parity is difficult to establish.

In this and a previous study ${ }^{4}$ oral contraceptive users had about $70 \%$ lower risk of borderline tumours. The protection provided by combined oral contraceptives on subsequent ovarian cancer risk is well established in epithelial invasive ovarian carcinogenesis. ${ }^{22.23}$ Similar, but not completely consistent, evidence emerged from functional and seromucinous ovarian cysts. ${ }^{24-27}$ These findings underline the protective effect of oral contraceptives on the whole spectrum of ovarian tumours.

Another potential similarity between borderline and invasive ovarian cancer ${ }^{21,28-31}$ concerns menstrual characteristics. In this study, no relationship was observed between borderline ovarian cancer and age at menarche, but cases did tend to report a later age at 
menopause, although this was not statistically significant. Similar findings emerged in an American casecontrol study. ${ }^{5}$

In conclusion, this study gives more detailed information on the epidemiology of borderline ovarian cancer and provides evidence of similarities between borderline and invasive ovarian tumour epidemiology including: a substantial protection by oral contraceptives on the two histological subtypes; a possible, although moderate, protective effect of high parity and of an early age at first birth; an increased risk in women with late age at menopause, but no substantial relationship with age at menarche. In biological terms these findings can be interpreted within the framework of the 'incessant ovulation' hypothesis in ovarian carcinogenesis, where ovulation or 'ovulatory cycles' are the relevant exposure which defines the incidence of the neoplastic lesions, thus suggesting an epidemiological continuum between various grades of malignancy of epithelial ovarian neoplasms.

\section{ACKNOWLEDGEMENTS}

This work was conducted within the framework of the CNR (Italian National Research Council) applied projects 'Oncology' and 'Risk factors for Disease' and with grants in aid from the Italian Ministry of Health and the 'Europe Against Cancer Programme' of the Commission of the European Communities. The generous contributions of the Italian Association for Cancer Research, and of the Italian League against Tumours, Milan, Italy, are gratefully acknowledged. Ms Judy Baggott, Ivana Garimoldi and the G A Pfeiffer Memorial Library Staff provided helpful editorial assistance.

\section{REFERENCES}

${ }^{1}$ Scully R E. Common epithelial tumors of borderline malignancy (carcinomas of low malignant potential). Bull Cancer (Paris) 1982; 69: 228-38.

${ }^{2}$ Hart W R. Ovarian epithelial tumors of borderline malignancy (carcinomas of low malignant potential). Human Pathol 1977; 8: 541-9.

${ }^{3}$ Harlow B L, Weiss N S, Lofton S. Epidemiology of borderline ovarian tumors. J Natl Cancer Inst 1987; 78; 71-4.

${ }^{4}$ Harlow B L, Weiss N S, Roth G J, Chu J, Daling J R. Case-control study of borderline ovarian tumors: reproductive history and exposure to exogenous female hormones. Cancer Research 1988; 48: 5849-52.

${ }^{5}$ McGowan L, Parent L, Lednar W, Norris, H J. The woman at risk for developing ovarian cancer. Gynecol Oncol 1979; 7: 325-44.

${ }^{6}$ Hildreth N G, Kelsey J L, LiVolsi V A, et al. An epidemiologic study of epithelial carcinoma of the ovary. Am J Epidemiol 1981; 114: 398-405.

${ }^{7}$ Cramer D W, Hutchison G B, Welch W R, Scully R E, Ryan K J. Determinants of ovarian cancer risk. I. Reproductive experiences and family history. J. Natl Cancer Inst 1983; i1: 711-6.

${ }^{8}$ Schildkraut J M, Thompson W D. Familial ovarian cancer: A population-based case-control study. $A m J$ Epidemiol 1988; 128: 456-66.

${ }^{9}$ Harlow B L, Weiss N S. Familial ovarian cancer: a populationbased case-control study. Am J Epidemiol 1989; 130: 1071-2.

${ }^{10}$ Serov S F, Scully R E, Sobin 1. International histologic classification of tumours, No. 9: Histological typing of ovarian tumors. Geneva: WHO, 1973.

11 La Vecchia C, Decarli A, Fasoli M, et al. Oral contraceptives and cancers of the breast and of the female genital tract. Interim results from a case-control study. Br J Cancer 1986; 54: 311-17.

12 Mantel N, Haenszel $W$. Statistical aspects of the analysis of data from retrospective studies of disease. J. Notl Cancer Inst 1959; 22: 719-48.

13 Mantel N. Chi-square tests with one degree of freedom: Extension of the Mantel-Haenszel procedure. J Am Stat Assoc 1963; 58: $690-700$.

14 Baker R J, Nelder J A. The GLIM System, Release 3. Oxford: Numerical Algorithms Group, 1978.

15 Davies M C, Hall M L, Jacobs H S. Bone mineral loss in young women with amenorrhoea. $\mathrm{Br}$ Med J 1990; 301: 790-3.

${ }^{16}$ Bean J A, Leeper J D, Wallace R B et al. Variations in the reporting of menstrual histories. Am J Epidemiol 1979; 109; 181-5.

${ }^{17}$ Hartge P, Schiffman M H, Hoover R, McGowan L, Lesher L, Norris A J. A case-control study of epithelial ovarian cancer. Am J Obstet Gynecol 1989; 161: 10-6.

${ }^{18}$ La Vecchia C, Pampallona S, Negri E, Fasoli M, Franceschi S, Decarli A. Characteristics of women undergoing induced abortion: Results of a case-control study from Northern Italy. Contraception 1985; 32: 637-49.

${ }^{19}$ Franceschi S. Reproductive factors and cancers of the breast, ovary and endometrium. Eur $J$ Cancer Clin Oncol. 1989; 25: 1933-43.

${ }^{20}$ La Vecchia C, Decarli A, Franceschi S, Regallo M, Tognoni G. Age at first birth and the risk of epithelial ovarian cancer. $J$ Natl Cancer Inst 1984; 73: 663-6.

${ }^{21}$ Booth R J, Beral V, Smith P. Risk factors for ovarian cancer: a case-control study. Br J Cancer 1989; 60: 592-8.

22 Prentice R L, Thomas D B. On the epidemiology of oral contraceptives and disease. Adv Cancer Res 1987; 49: 285-401.

${ }^{23}$ La Vecchia C, Franceschi S, Bruzzi P, Parazzini F, Boyle P. The relationship between oral contraceptive use, cancer and vascular disease. Drug Safety 1990; 5: 436-46.

${ }^{24}$ Ory H. Functional ovarian cysts and oral contraceptives. Negative association confirmed surgically. JAMA 1974; 228: 68-9.

${ }^{25}$ Vessey M, Doll R, Peto R, Johnson B, Wiggins P. A long-term follow-up study of women using different methods of contraception. An interim report. J Biosoc Sci 1976; 8: 373-427.

${ }^{26}$ Vessey M, Doll R, Peto R, Johnson B, Wiggins P. A long-term follow-up study of women using different methods of contraception. An interim report. J. Biosoc Sci 1976; 8: 373-427.

${ }^{27}$ Parazzini F, La Vecchia C, Franceschi S, Negri E, Cecchetti G. Risk factors for endometrioid, mucinous and serous benign ovarian cysts. Int J Epidemiol 1989; 18: 108-12.

${ }^{28}$ Kvale G, Heuch I, Nilssen S, Beral V. Reproductive factors and risk of ovarian cancer: A prospective study. Int J Cancer 1988; 42 : 246-51.

29 Tzonou A, Day N E, Trichopoulos D, et al. The epidemiology of ovarian cancer in Greece: A case-control study. Eur J Cancer Clin Oncol 1984; 20: 1045-52. 
${ }^{30}$ Parazzini F, La Vecchia C, Negri E, Gentile A. Menstrual factors and the risk of epithelial ovarian cancer. $J$ Clin Epidemiol 1989; 42: 443-8.

${ }^{31}$ Shu X O, Brinton L A, Gao Y T, Yuan J M. Population-based case-control study of ovarian cancer in Shanghai. Cancer Res 1989; 49: 3670-4.
${ }^{32}$ Parazzini F, La Vecchia C, Negri E, Bocciolone L, Fedele L. Ora! contraceptive use and the risk of ovarian cancer: another Italian case-control study. Eur J Cancer 1991; 27: 594-98.

(Revised version received May 1991) 